\title{
Synergistic anticancer effect of curcumin and chemotherapy regimen FP in human gastric cancer MGC-803 cells
}

\author{
BIN HE ${ }^{1,2}$, WEN WEI ${ }^{1}, \mathrm{JI}^{\mathrm{LI}}{ }^{1}, \mathrm{YUNDAN}^{\mathrm{X}}{ }^{1}$ and GANG ZHAO ${ }^{1}$ \\ ${ }^{1}$ Department of Medical Biology, School of Basic Medical Sciences, Hubei University of Chinese Medicine, \\ Wuhan, Hubei 430065; ${ }^{2}$ Department of Traditional Chinese Medicine, The Third People's Hospital of \\ Hubei (Zhongshan Hospital of Hubei), Wuhan, Hubei 430033, P.R. China
}

Received September 28, 2015; Accepted March 14, 2017

DOI: $10.3892 / \mathrm{ol} .2017 .6627$

\begin{abstract}
Curcumin is an anticancer compound that exerts anti-proliferative and apoptotic effects via multiple molecular targets. The purpose of the present study was to investigate the anticancer effects of curcumin in combination with 5-fluorouracil plus cisplatin (FP) on the MGC-803 human gastric cancer cell line. Following treatment with curcumin and/or FP for 24, 48 and $72 \mathrm{~h}$, cell viability, cell cycle progression and the apoptosis rate were evaluated using an MTT assay, flow cytometry and dual acridine orange/ethidium bromide staining, respectively. In addition, colony formation, Transwell migration and caspase-3/caspase- 8 activity assays were performed. The expression of the apoptosis regulator B-cell lymphoma-2 (Bcl-2) and Bcl-2-associated X protein (Bax) were detected by western blotting analysis. Following treatment with curcumin and/or FP, cell viability, colony formation and cell migration were significantly reduced compared with the untreated control group. The rate of apoptosis, caspase-3/caspase- 8 activity and the expression of Bax were significantly increased, whereas Bcl-2 expression was significantly reduced following treatment with curcumin and/or FP, compared with the untreated control group. The efficacy of curcumin combined with low-dose FP was significantly increased, compared with that of curcumin combined with high-dose FP $(\mathrm{P}<0.05)$. Therefore, curcumin may enhance the anticancer effects of FP chemotherapy in MGC-803 cells through the promotion of apoptosis via the caspase-3/caspase- 8 , Bcl-2 and Bax signaling pathways. These results suggest that curcumin may serve as a synergistic drug
\end{abstract}

Correspondence to: Professor Gang Zhao, Department of Medical Biology, School of Basic Medical Sciences, Hubei University of Chinese Medicine, 1 Huangjiahu West Road, Hongshan, Wuhan, Hubei 430065, P.R. China

E-mail: zgcc66@163.com

Key words: curcumin, 5-fluorouracil plus cisplatin, gastric cancer, MGC-803 cells, synergistic anticancer effect, proliferation, apoptosis with chemotherapy regimen FP for the treatment of gastric cancer.

\section{Introduction}

Gastric cancer (GC) is one of the most invasive and aggressive malignancies and remains a major health problem worldwide due to its high incidence and mortality rate (1). Despite a steady decline in GC incidence, GC is currently the third highest cause of cancer-associated mortality worldwide, with 730,000 patients succumbing to the disease every year $(2,3)$. Patient survival is primarily associated with disease stage, and the cure rate largely depends upon surgical resection. However, $<5 \%$ of patients with advanced GC may survive $\leq 5$ years and the role of surgery as a mainstay treatment is limited to $\sim 25 \%$ of all patients (4). Chemotherapy has served a major role in the treatment of gastric cancer over the past twenty years. The 5-fluorouracil (5'-FU) plus cisplatin (DDP) regimen (FP) of chemotherapy consists of the continuous infusion of 5-FU with low-dose DDP, which is typically used to treat GC; however, the success rate of this treatment is limited due to the development of chemoresistance and toxic side effects. Therefore, a novel chemotherapy regimen that will improve clinical outcomes is required for patients with GC.

One strategy to improve anticancer treatment regimens may be to combine conventional chemotherapeutics with natural antitumor compounds. Curcumin, also known as 1,7-bis (4-hydroxy-3methoxyphenol)-1,6-heptadiene-3,5-dione, is obtained and purified from turmeric (Curcuma longa), which belongs to the Zingiberaceae plant family indigenous to southern and southeastern tropical Asia (5). It has been widely used as a spice, to color cheese and butter, as a cosmetic and in certain medicinal preparations (6). The safety of Curcuma has been investigated in various animal models, and it has been established that turmeric is not toxic even at high doses (7). Previous studies have suggested that curcumin has a number of pharmacological effects, including anti-inflammatory, antioxidant and anticancer properties (8-10).

In the present study, the effects and underlying molecular mechanisms of curcumin combined with the FP regimen of chemotherapy were investigated in the MGC-803 human gastric cancer cell line. The results may aid with developing novel treatment strategies for patients with GC. 


\section{Materials and methods}

Cell culture and reagents. MGC-803 cells were purchased from the Cell Bank of Type Culture Collection of Chinese Academy of Sciences (Shanghai, China). The cells were maintained in RPMI-1640 medium (HyClone; GE Healthcare Life Sciences, Logan, UT, USA), supplemented with $2 \mathrm{mmol} / \mathrm{l}$ L-glutamine, $100 \mathrm{U} / \mathrm{ml}$ penicillin, $0.1 \mu \mathrm{g} / \mathrm{ml}$ streptomycin and $10 \%$ fetal bovine serum (FBS, Tianhang Biotechnology Co., Ltd., Zhejiang, China) at $37^{\circ} \mathrm{C}$ in a humidified atmosphere containing $5 \% \mathrm{CO}_{2}$. The culture medium was replaced once every two days. Curcumin was purchased from Sigma-Aldrich (Merck KGaA, Darmstadt, Germany). DDP was purchased from Qilu Pharmaceutical Co., Ltd. (Shandong, China). The 5-FU was purchased from Tianjin Jinyao Amino Acid Co., Ltd. (Tianjin, China).

Cell groups. There were six treatment groups used in the present study, as follows: Control (curcumin or FP concentration at $0 \mu \mathrm{mol} / 1)$; CUR ( $15 \mu \mathrm{mol} / 1$ curcumin); CUR+LD FP [curcumin $(15 \mu \mathrm{mol} / \mathrm{l})$ combined with low dose FP $(25 \mu \mathrm{mol} / 15-\mathrm{FU}+1 \mu \mathrm{mol} / 1 \mathrm{DDP})]$; CUR+MD FP [curcumin $(15 \mu \mathrm{mol} / \mathrm{l})$ combined with medium dose FP $(50 \mu \mathrm{mol} / 15-\mathrm{FU}+2 \mu \mathrm{mol} / \mathrm{l} \mathrm{DDP})]$; MD FP [medium dose FP $(50 \mu \mathrm{mol} / 15-\mathrm{FU}+2 \mu \mathrm{mol} / 1 \mathrm{DDP})]$ and HD FP [high dose FP $(100 \mu \mathrm{mol} / 15-\mathrm{FU}+4 \mu \mathrm{mol} / 1 \mathrm{DDP})]$.

Cell viability assay. Cells were seeded in 96-well plates at a concentration of $4 \times 10^{3}$ cells/well. Following incubation for $12 \mathrm{~h}$ at $37^{\circ} \mathrm{C}$, curcumin and/or low, medium or high dose FP at the aforementioned concentrations were added. There were 8 duplicate wells for each group with a total volume of $200 \mu 1 /$ well. Following treatment for 24,48 and $72 \mathrm{~h}$ at $37^{\circ} \mathrm{C}$ in an atmosphere of $5 \% \mathrm{CO}_{2}, 20 \mu 1 \mathrm{MTT}$ solution (Sigma-Aldrich; Merck KGaA) at a concentration of $5 \mathrm{~g} / \mathrm{l}$ was added to each well, then the plates were incubated for $4 \mathrm{~h}$. Dimethyl sulfoxide (DMSO; $150 \mu \mathrm{l}$; Sigma-Aldrich; Merck KGaA) was added to each well prior to agitation for $10 \mathrm{~min}$ at room temperature. A Model 680 microplate reader (Bio-Rad Laboratories, Inc., Hercules, CA, USA) was used to measure the absorbance at $570 \mathrm{~nm}$. The inhibitory rate (\%) was calculated using the following equation: Inhibitory rate $(\%)=[(1-$ optical density $\left.\left.(\mathrm{OD})_{\mathrm{E}} / \mathrm{OD}_{\mathrm{C}}\right)\right] \times 100 \% . \mathrm{OD}_{\mathrm{E}}$ represents the OD value of the experimental group with drug treatment; $\mathrm{OD}_{\mathrm{C}}$ represents the OD value of the control group without drug treatment. The experiment was repeated $\geq 3$ times.

Flow cytometry. Cells were seeded at a density of $4 \times 10^{5}$ cells/well in 6-well culture plates (Corning Incorporated, Corning, NY, USA) for $24 \mathrm{~h}$, and treated with/without curcumin and/or FP at various concentrations for $24 \mathrm{~h}$ at $37^{\circ} \mathrm{C}$ in an atmosphere of $5 \% \mathrm{CO}_{2}$. Apoptosis was then analyzed by flow cytometry using Annexin V-fluorescein isothiocyanate (FITC) and propidium iodide (PI; each purchased from Sungene Biotech Co., Ltd., Tianjin, China) double staining. Prior to flow cytometry analysis, the cells were collected, washed with cold PBS twice and resuspended gently in $400 \mu \mathrm{l}$ binding buffer. Annexin V-FITC (5 $\mu$ l) was added to the cells and the samples were gently vortexed prior to incubation for $10 \mathrm{~min}$ at $4^{\circ} \mathrm{C}$ in the dark. PI $(10 \mu \mathrm{l})$ was added and the samples were incubated for another $5 \mathrm{~min}$ at $4^{\circ} \mathrm{C}$ in the dark. Flow cytometry was then conducted using a FACSCalibur ${ }^{\mathrm{TM}}$ flow cytometer (BD Biosciences, Franklin Lakes, NJ, USA), and the results were analyzed with BD CellQuest ${ }^{\mathrm{TM}}$ software (version 5.1; BD Biosciences). The experiment was repeated $\geq 3$ times.

Cell cycle analysis was performed using PI $(40 \mu \mathrm{g} / \mathrm{ml})$ single staining with a flow cytometer. Prior to analysis, cells were washed in PBS containing 2\% FBS and the resulting pellet was resuspended in DNase-free RNase $(200 \mu \mathrm{g} / \mathrm{ml}$, $0.5 \mathrm{ml})$ for $2 \mathrm{~h}$ at $37^{\circ} \mathrm{C}$. Cells were then stained with PI and analyzed by flow cytometry. The data were analyzed using ModFit LT ${ }^{\text {TM }}$ software (version 3.0; Verity Software House, Topsham, ME, USA) and expressed as the percentage of cells in each phase of the cell cycle. The experiment was repeated $\geq 3$ times.

Dual acridine orangelethidium bromide (AO/EB) fluorescent staining. Cells were seeded at a density of $4 \times 10^{5}$ cells/well, cultured in 6-well culture plates (Corning Incorporated) for $24 \mathrm{~h}$ and treated with/without curcumin and/or FP at various concentrations for $24 \mathrm{~h}$. The medium was removed. Trypsin $(0.25 \%$; HyClone; GE Healthcare Life Sciences) was added into each well. When the cells had detached, the suspensions $(25 \mu \mathrm{l})$ were transferred to glass slides. Dual fluorescent staining solution (1 $\mu \mathrm{l})$ containing $100 \mu \mathrm{g} / \mathrm{ml} \mathrm{AO}$ and $100 \mu \mathrm{g} / \mathrm{ml}$ EB (Sigma-Aldrich; Merck KGaA) was added to each suspension and then covered with a coverslip. The morphology of apoptotic cells was examined and 1,000 cells were counted within 20 min based on randomly chosen fields of view using a fluorescent microscope (Nikon Corporation, Tokyo, Japan). The apoptotic percentage was expressed as a ratio of the number of apoptotic cells in the experimental groups (curcumin and/or FP at low, medium or high dose) compared with that in the untreated control group. The experiment was repeated $\geq 3$ times.

Colony formation assay. The 6-well culture plates were seeded with $\sim 500$ viable MGC- 803 cells and incubated at $37^{\circ} \mathrm{C}$ in an atmosphere of $5 \% \mathrm{CO}_{2}$ for $24 \mathrm{~h}$. The cells were then incubated with various concentrations of curcumin and $\mathrm{FP}$ at $37^{\circ} \mathrm{C}$ in an atmosphere of $5 \% \mathrm{CO}_{2}$ for $24 \mathrm{~h}$. The curcumin and/or FP containing medium was then removed, and the cells were washed in PBS and incubated for an additional 10 days in complete medium. The colonies obtained were washed with PBS and fixed in methanol-acetic acid (3:1) stationary liquid for $10 \mathrm{~min}$ at room temperature, and then washed with PBS followed by staining with Giemsa (10\%; Sigma-Aldrich; Merck $\mathrm{KGaA})$. The colonies were counted and compared with in the untreated control group. The inhibitory rate was expressed as a ratio of the number of colonies in the experimental groups (curcumin and/or FP at low, medium or high dose) compared with in the untreated control group.

Transwell migration assay. A Transwell migration assay (Corning Incorporated) was performed according to the manufacturer's protocol in 24-well plates. MGC-803 cells were cultured in RPMI-1640 medium for 5 days, then the cells $\left(1 \times 10^{5}\right)$ in $100 \mu 1$ serum-free medium with/without curcumin and/or FP at various concentrations were seeded into the upper 
chamber of an 8-mm pore size Transwell insert. The lower chambers in the system were filled with Dulbecco's modified Eagle's medium (HyClone; GE Healthcare Life Sciences, Logan, UT, USA) supplemented with $10 \%$ FBS. After $10 \mathrm{~h}$ of incubation, non-migratory cells in the upper chamber were removed. MTT solution (100 $\mu \mathrm{l} ; 5 \mathrm{~g} / \mathrm{l})$ was added to each well, then the 24-well plate was incubated at $37^{\circ} \mathrm{C}$ in an atmosphere of $5 \% \mathrm{CO}_{2}$ for $4 \mathrm{~h}$. DMSO $(150 \mu \mathrm{l})$ was added to each well prior to agitation for $10 \mathrm{~min}$ at room temperature. The absorbance was measured using a microplate reader at $570 \mathrm{~nm}$. The migration rate $(\%)$ was calculated using the following equation: Migration rate $\left(\%=\left(\mathrm{OD}_{\mathrm{E}} / \mathrm{OD}_{\mathrm{C}}\right) \times 100 \%\right.$. The experiment was repeated $\geq 3$ times.

Determination of caspase-3 and caspase-8 activity. MGC-803 cells were seeded in a 6 -well culture plate at a density of $4 \times 10^{6}$ cells/well, and treated with or without curcumin and/or $\mathrm{FP}$ at the aforementioned concentrations for $24 \mathrm{~h}$. The medium was removed, and the MGC- 803 cells were washed three times with PBS for 1 min each time, digested with Trypsin ( $0.25 \%$; HyClone; GE Healthcare Life Sciences), and collected by centrifuging at $600 \mathrm{xg}$ for $5 \mathrm{~min}$ at $4^{\circ} \mathrm{C}$. The activities of caspase- 3 and caspase- 8 were measured using a caspase- 3 activity assay kit and caspase- 8 activity assay kit (Applygen Technologies Inc., Beijing, China) according to the manufacturer's protocol. Each sample was measured in triplicate. Relative caspase-3 activity was expressed as the absorbance compared with the untreated control group based on the following equation: Relative activity $=\mathrm{OD}$ of experimental group/OD of control group.

Western blot analysis. Cells were seeded at a density of $4 \times 10^{6}$ cells/well in a 6 -well culture plate and treated with or without curcumin and/or FP at various concentrations for $24 \mathrm{~h}$. A total of $1 \times 10^{6}$ cells/well were acquired by cell scraper, washed with PBS and then suspended in $250 \mu \mathrm{l}$ lysis buffer (pH 7.5, 1\% Triton-X-100, 40 mmol/1 Tris-HCl, $150 \mathrm{mmol} / \mathrm{l}$ $\mathrm{KCl}, 1 \mathrm{mmol} / 1 \mathrm{EDTA}, 100 \mathrm{mmol} / 1 \mathrm{NaVO} 3$ and $1 \mathrm{mmol} / \mathrm{l}$ phenylmethylsulfonyl fluoride). Following protein extraction and concentration detection (BCA Protein Assay Kit;, Beyotime Biotechnology Co., Ltd., Haimen, China), proteins were separated using SDS-PAGE and then transferred to polyvinylidene fluoride membranes (EMD Millipore, Billerica, MA, USA). The membranes were blocked with 5\% skimmed milk. The membranes were then incubated with antibodies against the apoptosis regulator B-cell lymphoma-2 (Bcl-2; cat. no. 13CM357; dilution 1:1,000; Boster Biological Technology Co., Ltd., Wuhan, China), Bcl-2-associated X protein (Bax; cat. no. 196841; dilution 1:1000; Boster Biological Technology Co., Ltd.) and $\beta$-actin (cat. no. E0610; dilution 1:1000; Kerui Biotechnology Co., Ltd., Wuhan, China) in TBS-Tween containing 5\% skimmed milk at $4^{\circ} \mathrm{C}$ for $12 \mathrm{~h}$. Following washing, the membranes were incubated with a horseradish peroxidase immunoglobulin $\mathrm{G}$ antibody (cat. no. BST10F01A; dilution 1:10,000; Sungene Biotech Co., Ltd., Tianjin, China) at room temperature for $1 \mathrm{~h}$. The blots were developed using an enhanced chemiluminescence kit (Thermo Fisher Scientific, Inc., Waltham, MA, USA). Quantification of immunoblot intensity was performed using ImageJ software (version 2.1.4.7; National Institutes of

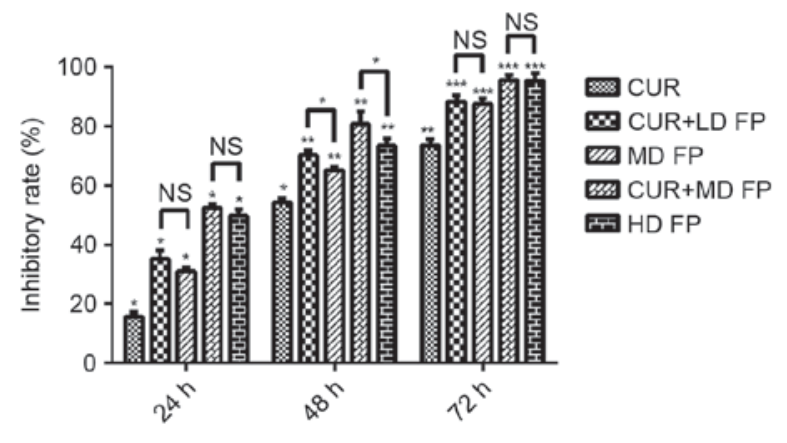

Figure 1. Effect of curcumin and/or FP treatment on the viability of MGC-803 cells. Cell viability was assessed using an MTT assay following treatment with curcumin and/or FP for 24,48 and $72 \mathrm{~h}$. The inhibitory rate was calculated compared with the viability of the untreated control cells. Data are presented as the mean \pm standard deviation and are representative of $\geq 3$ independent experiments. Compared with control: ${ }^{*} \mathrm{P}<0.05,{ }^{* *} \mathrm{P}<0.01$, ${ }^{* * * *} \mathrm{P}<0.005$. FP, 5'-fluorouracil plus cisplatin; CUR, curcumin; LD, low-dose; MD, low-dose; HD, high-dose; NS, not significant.

Health, Bethesda, MD, USA). The experiment was repeated $\geq 3$ times.

Statistical analysis. Data analyses were performed using SPSS software (version 16.0; SPSS Inc., Chicago, IL, United States). Data are presented as the mean \pm standard deviation. Group comparisons were evaluated using a one-way analysis of variance. Two-sided tests were used to evaluate comparisons between two groups. $\mathrm{P}<0.05$ was considered to indicate a statistically significant difference.

\section{Results}

The effect of curcumin and/or FP on the viability of MGC-803 cells. An MTT assay was used to examine the effect of curcumin and FP on MGC-803 cell viability following drug treatment for 24, 48 and $72 \mathrm{~h}$. All treatments significantly decreased cell viability compared with the untreated control $\left({ }^{*} \mathrm{P}<0.05,{ }^{* *} \mathrm{P}<0.01,{ }^{* * *} \mathrm{P}<0.005\right.$. Fig. 1). Following drug treatment for 24 and $72 \mathrm{~h}$, no significant differences were observed between the MD FP and CUR+LD FP groups, or between the HD FP and CUR+MD FP groups. However, treatment with CUR+LD FP for $48 \mathrm{~h}$ significantly decreased cell viability compared with the MD FP treatment group $(\mathrm{P}<0.05)$, and treatment with CUR+MD FP for $48 \mathrm{~h}$ significantly decreased cell viability compared with the HD FP group $(\mathrm{P}<0.05)$. Therefore, curcumin enhanced the effects of FP on MGC-408 cell viability.

Effect of curcumin and/or FP on the apoptosis and cell cycle of $M G C-803$ cells. Flow cytometry was performed to investigate the effect of curcumin and/or FP on the apoptosis and cell cycle of MGC-803 cells. Compared with the controls, all drug treatments significantly increased the percentage of apoptotic cells (Fig. 2A and B). The apoptotic percentages of the combined groups were significantly higher than for the FP treatment groups $24 \mathrm{~h}$ following treatment $(\mathrm{P}<0.01$; CUR+LD FP vs. MD FP; CUR+MD FP vs. HD FP). The apoptotic percentage was examined using two staining methods 


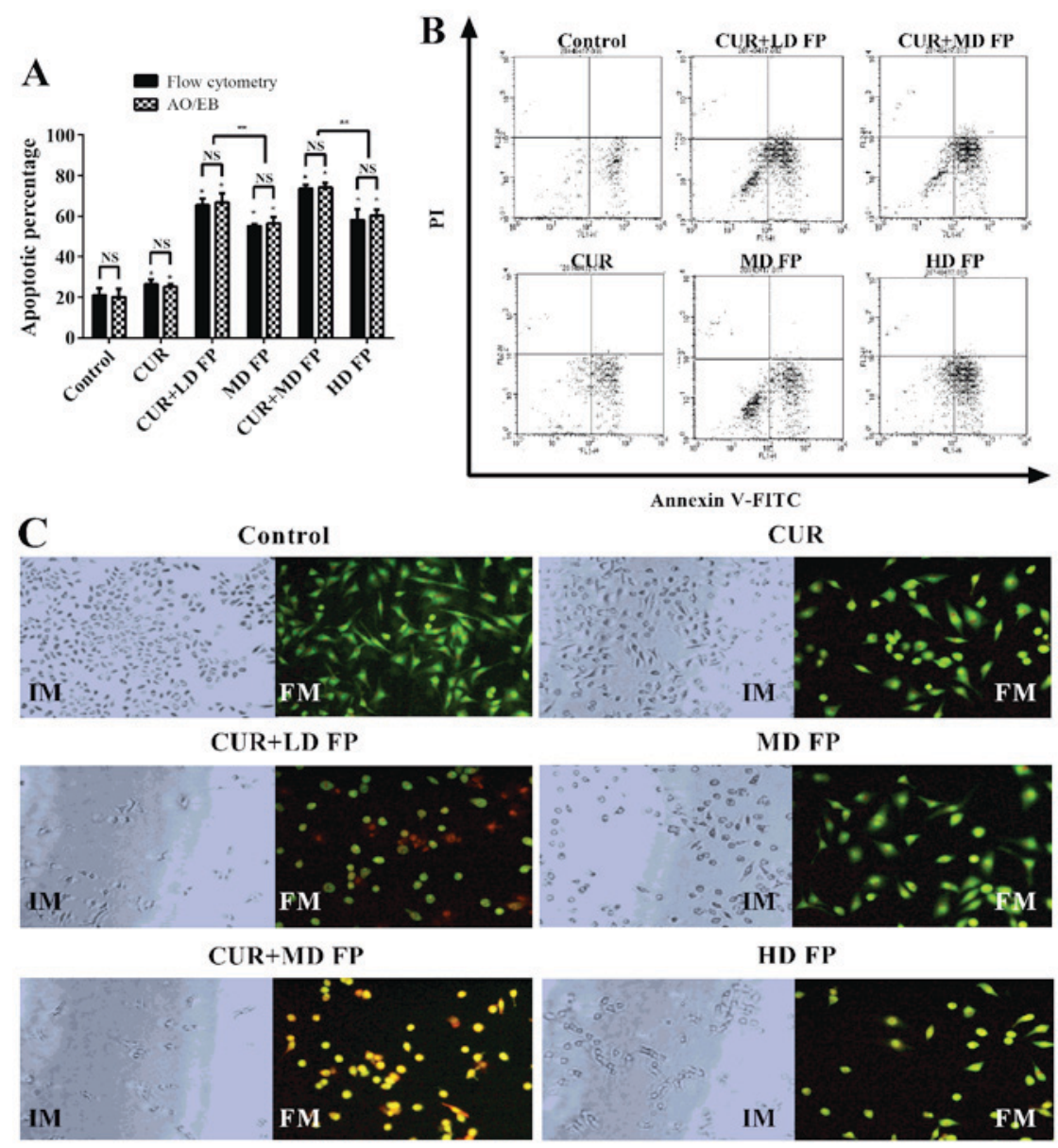

Figure 2. Effect of curcumin and/or FP treatment on MGC-803 cell apoptosis. (A) The percentage of apoptotic MGC-803 cells following treatment with curcumin and/or FP for $24 \mathrm{~h}$, measured using Annexin V-FITC/PI staining and dual AO/EB staining. (B) Representative flow cytometry charts of Annexin V-FITC/PI staining in untreated (control) MGC-803 cells and cells treated with curcumin and/or FP. (C) Morphological changes, imaged with an IM, and dual AO/EB staining, imaged with a FM, of MGC-803 cells following treatment with curcumin and/or FP. Magnification, $\mathrm{x} 200$. Data are representative of $\geq 3$ independent experiments. ${ }^{*} \mathrm{P}<0.05,{ }^{* * *} \mathrm{P}<0.01$. FP, $5^{\prime}$-fluorouracil plus cisplatin; FITC, fluorescein isothiocyanate; PI, propidium iodide; AO, acridine orange; EB, ethidium bromide; CUR, curcumin; LD, low-dose; MD, low-dose; HD, high-dose; IM, inverted microscope; FM, fluorescence microscope.

(Annexin V-FITC/PI and dual AO/EB staining). The results of dual AO/EB staining also demonstrated that curcumin significantly increased FP-induced cell apoptosis $(\mathrm{P}<0.05)$ and no significant differences were observed between the apoptotic percentage measured by Annexin V-FITC/PI flow cytometry and by AO/EB ( $\mathrm{P}>0.05$; Fig. 1A). These results demonstrated that curcumin increases the level of FP-induced cell apoptosis.

Following treatment with curcumin and/or FP for $24 \mathrm{~h}$, there were marked changes in cellular morphology, including cell shrinkage and nuclear fragmentation in the drug treatment groups, compared with in the control group (Fig. 2C). For the non-apoptotic cells, the nucleus was circular and uniformly distributed in the center of the cell. For early apoptotic cells, the nucleus exhibited yellow-green fluorescence by $\mathrm{AO}$ staining and concentrated into a crescent or granular nucleus that was located on one side of the cell. For late apoptotic cells, the nucleus exhibited orange fluorescence by EB staining, and, the chromatin condensed and distributed around the nuclear membrane. For necrotic cells, the cell volume was increased, and the nucleus exhibited uneven orange-red fluorescence and an unapparent outline, indicating it was disintegrating.
Cell cycle analysis demonstrated that there was a change in $S$ phase arrest in response to treatment with curcumin and/or FP compared with the control group (Fig. 3). Treatment with FP alone resulted in cell arrest at S phase (MD FP 30.32\%, HD FP 47.77\%), whereas combined treatment resulted in a significant increase in the number of cells arrested at the $S$ phase, compared with the control group and the FP treatment groups (CUR+LD FP 38.23\%, CUR+MD FP 76.38\%; P<0.05; Fig. 3B).

Impact of curcumin and/or FP on the colony formation and migration ability of $M G C-803$ cells. A colony formation assay demonstrated that the proliferation rate and colony numbers of the MGC-803 cells treated with curcumin and/or FP were significantly decreased compared with the control group $(\mathrm{P}<0.05$; Fig. $4 \mathrm{~A}$ and $\mathrm{B})$. The inhibitory rate of the combined treatment group was significantly higher compared with that of the FP treatment group (CUR+LD FP $38.1 \%$ vs. MD FP $31.9 \%$, CUR+MD FP $68.1 \%$ vs. HD FP 40\%; P<0.01; Fig. 4B). In addition, a significantly lower number of cells migrated through the Transwell filter when curcumin and/or FP were added into the migration chamber, as compared with the untreated control group without curcumin and FP $(\mathrm{P}<0.05$; 

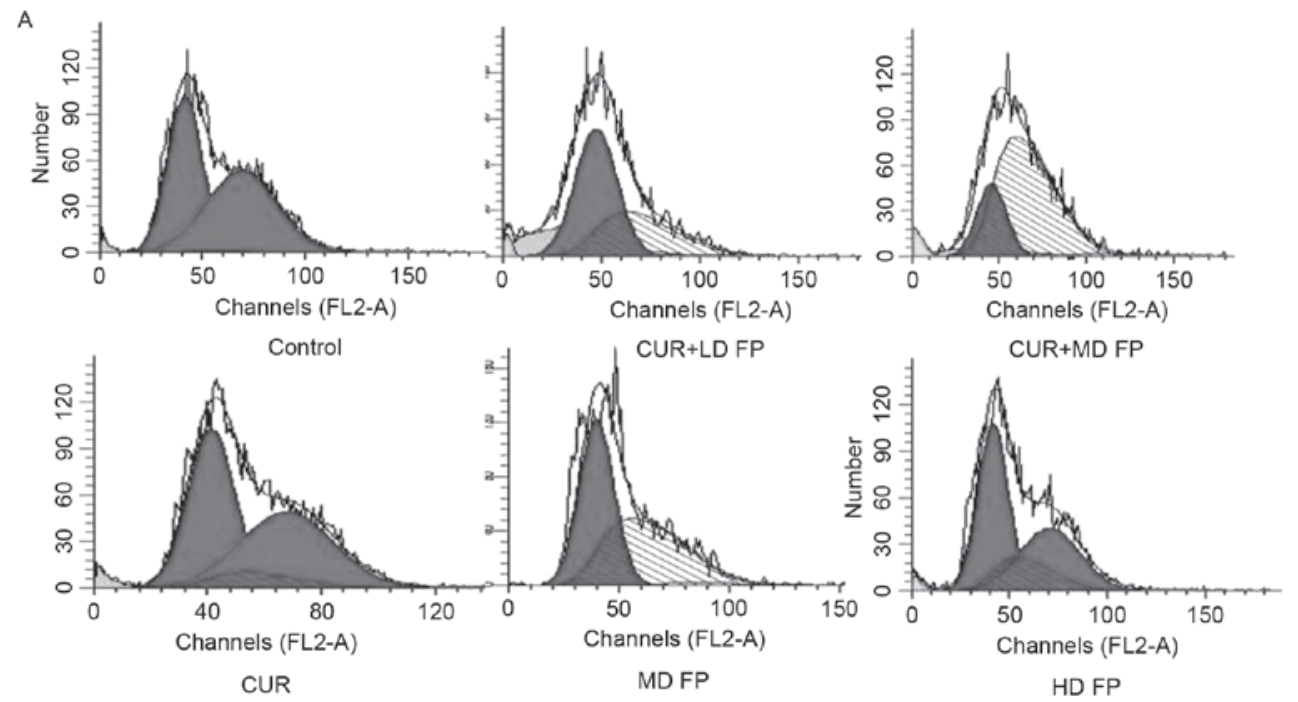

B

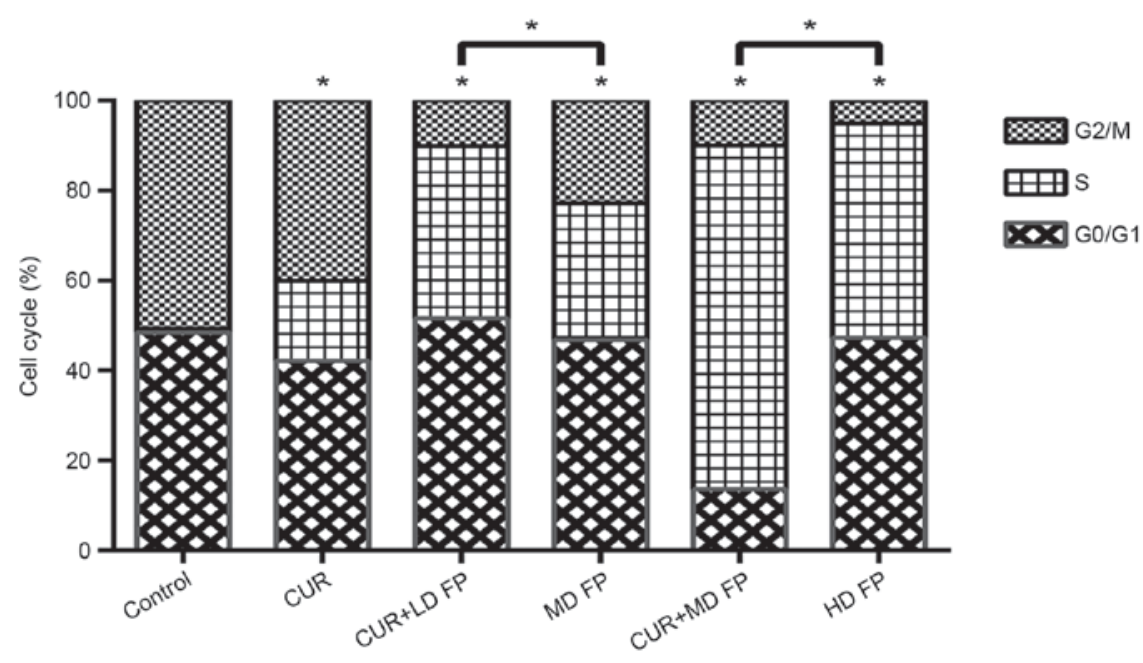

Figure 3. Effect of curcumin and/or FP on the cell cycle of MGC-803 cells. (A) Flow cytometry charts of propidium iodide staining in untreated (control) MGC-803 cells or MGC-308 cells treated with curcumin and/or FP. (B) Quantification of flow cytometry analysis of cell cycle distribution. Data are representative of $\geq 3$ independent experiments. "P<0.05. FP, 5'-fluorouracil plus cisplatin; CUR, curcumin; LD, low-dose; MD, low-dose; HD, high-dose.

Fig. 4C). No significant differences were observed in the migration rate of the combined treatment group compared with that of the FP treatment group ( $>>0.05$; Fig. 4C). Overall, curcumin enhanced the effects of FP treatment on cell viability, and the colony formation and migration abilities of MGC-803 cells.

Effect of curcumin and/or FP on the expression and activity of apoptosis-associated proteins in MGC-803 cells. To investigate the underlying molecular mechanisms of the effects of combined curcumin and FP treatment on MGC- 803 apoptosis the expression and activity of apoptosis-associated proteins was investigated using western blot analysis and activity assay kits, respectively, including Bcl-2, Bax, caspase- 3 and caspase-8. Treatment with curcumin and/or FP significantly decreased the expression of $\mathrm{Bcl}-2$ and increased the expression of Bax, compared with in the untreated control group $(\mathrm{P}<0.05$; Fig. 5A and B). Bcl-2 expression was significantly higher in the combined treatment groups compared with in the FP treatment groups (CUR+LD FP 0.19 vs. MD FP
0.52, CUR+MD FP 0.09 vs. HD FP 0.37; P<0.01; Fig. 5B). However, no significant differences were observed in Bax expression between the combined treatment groups and the FP treatment groups.

The relative caspase- 3 and caspase- 8 activities of the drug treatment groups with curcumin and/or FP were significantly elevated compared with the untreated control group without curcumin and FP $(\mathrm{P}<0.05$, or $\mathrm{P}<0.01$ for the CUR+MD FP group; Fig. 5C). The relative caspase- 3 and caspase- 8 activities of the CUR+MD FP group were significantly higher compared with those of the HD FP group (caspase-3: 22.1 vs. 12.5 ; caspase-8: 20.1 vs. 11.3 ; $\mathrm{P}<0.05$; Fig. 5 C), whereas no significant differences were observed between the caspase-3/caspase- 8 activities of the CUR+LD FP group and the MD FP group (caspase-3: 11.6 vs. 7.86; caspase-8: 10.4 vs. 6.54 ; P $>0.05$; Fig. 5 C). These data suggest that curcumin enhances the apoptotic effects of FP treatment in MGC-803 cells via the promotion of $\mathrm{Bcl}-2$ and the inhibition of Bax, followed by elevating the activation of caspase- 3 and caspase-8. 


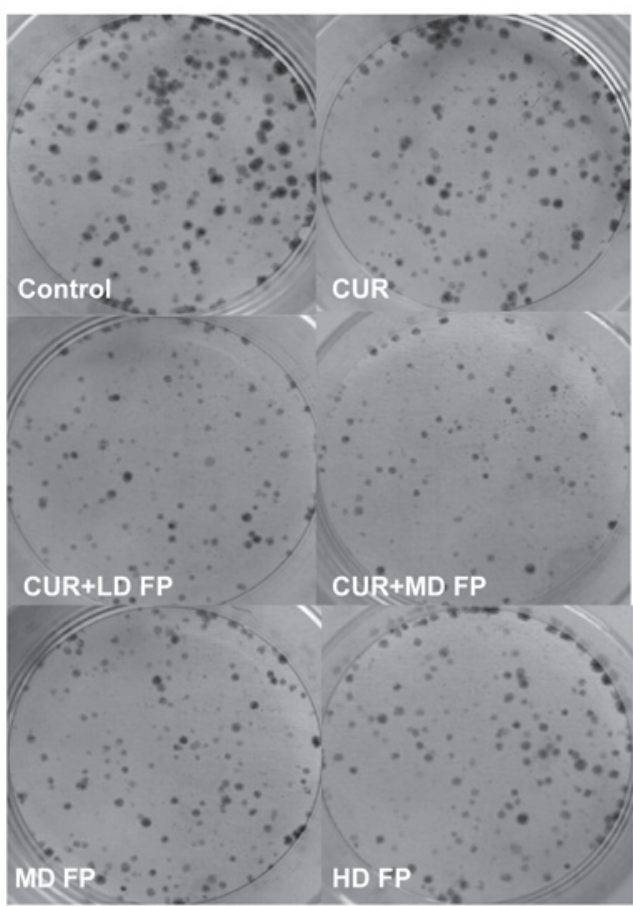

A

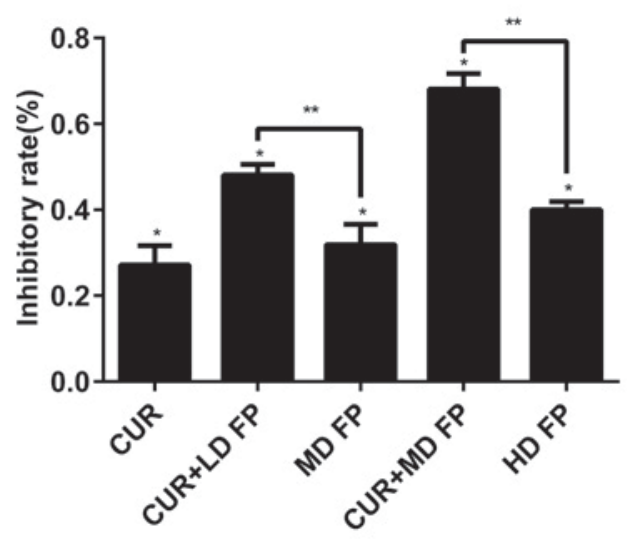

B

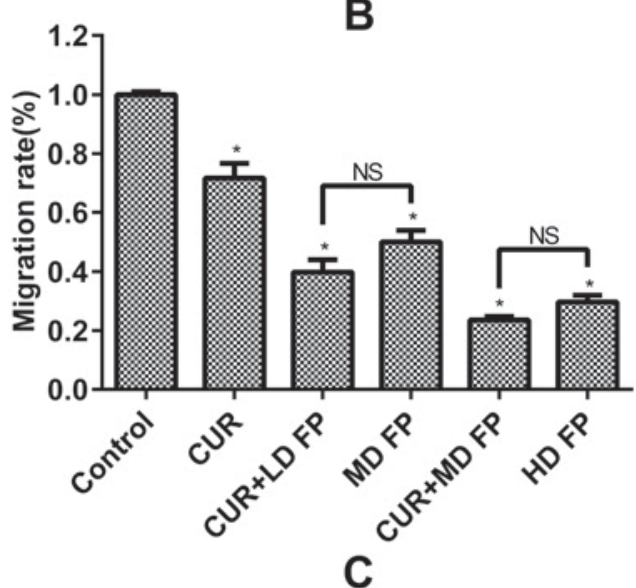

Figure 4. Effect of curcumin and/or FP on the colony formation and migration abilities of MGC-803 cells. (A) Representative images of the colony formation assay of MGC-803 cells following treatment with curcumin and/or FP for $24 \mathrm{~h}$ (magnification, x1.5). (B) Inhibitory rate of MGC-803 cells calculated from the colony formation assay. (C) Transwell migration assay with MGC-803 cells following treatment with curcumin and/or FP. Data are presented as the mean \pm standard deviation and is representative of $\geq 3$ independent experiments. ${ }^{*} \mathrm{P}<0.05,{ }^{* *} \mathrm{P}<0.01$. FP, 5'-fluorouracil plus cisplatin; CUR, curcumin; LD, low-dose; MD, low-dose; HD, high-dose; NS, not significant.

\section{Discussion}

$\mathrm{GC}$ is one of the most common types of malignant tumor (1). It has previously been reported that, although $>50 \%$ of patients diagnosed with GC successfully undergo surgical tumor resection, $60 \%$ of those patients subsequently present with local recurrence or distant metastasis (11). Chemotherapy remains an indispensable form of treatment, particularly for patients with advanced stage GC. Regimens based on 5-FU and DDP treatments have been a typical approach for patients with GC. The synergistic effect between 5-FU and DDP was reported as early as the end of the 1970s (12). FP as a combination chemotherapy regimen was established for the treatment of cancer, particularly for patients with advanced-stage cancer $(13,14)$. FP primarily exerts its cytotoxic effects by inhibiting enzyme activity, preventing the synthesis of DNA, blocking cell cycle progression and promoting apoptosis (15). The effect of 5-FU is enhanced by low-dose DDP. However, chemotherapy resistance and side effects have become challenges for the treatment of cancer using this method. Thus, it is essential to explore alternative effective anticancer chemotherapy regimens.

Curcumin is a plant polyphenol extracted from the spice turmeric (Curcuma longa), which is used as an herbal remedy in traditional Chinese and Indian medicine (5). The efficacy, pharmacological safety and cost effectiveness of curcumin and no observed toxicity make it an ideal compound to investigate for its anticancer properties $(16,17)$. Curcumin has previously been reported to possess anti-inflammatory, antioxidant, anticarcinogenic, antimutagenic, anticoagulant, antiarthritic, antibacterial, antifungal, antiprotozoal, antiviral, anti-Alzheimer, anti-psoriatic and neuroprotective activities (18-20). Curcumin exerts anti-proliferative and apoptotic effects in various types of cancer, including lung, ovarian, esophageal and liver cancer, in addition to glioma (21-26). The molecular mechanisms underlying the anticancer effects of curcumin are complex. Previous studies have demonstrated that curcumin can mediate apoptosis through the upregulation of caspase- 8 and caspase-3 (27). Curcumin may also able to attenuate the incidence of cancer via the reduction of phospho-Iк $\mathrm{B} \alpha$ and 8-OHdG expression during tumor initiation (28). In addition, curcumin may reduce the invasive ability of A431 cells by inhibiting the activation of the STAT3 signaling pathway and the expression of STAT3 as a target gene in the pathway (29).

Curcumin has been reported to inhibit the activation of myeloid-derived suppressor cells (MDSCs), promote the 
A

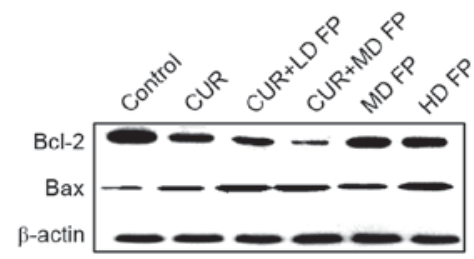

B
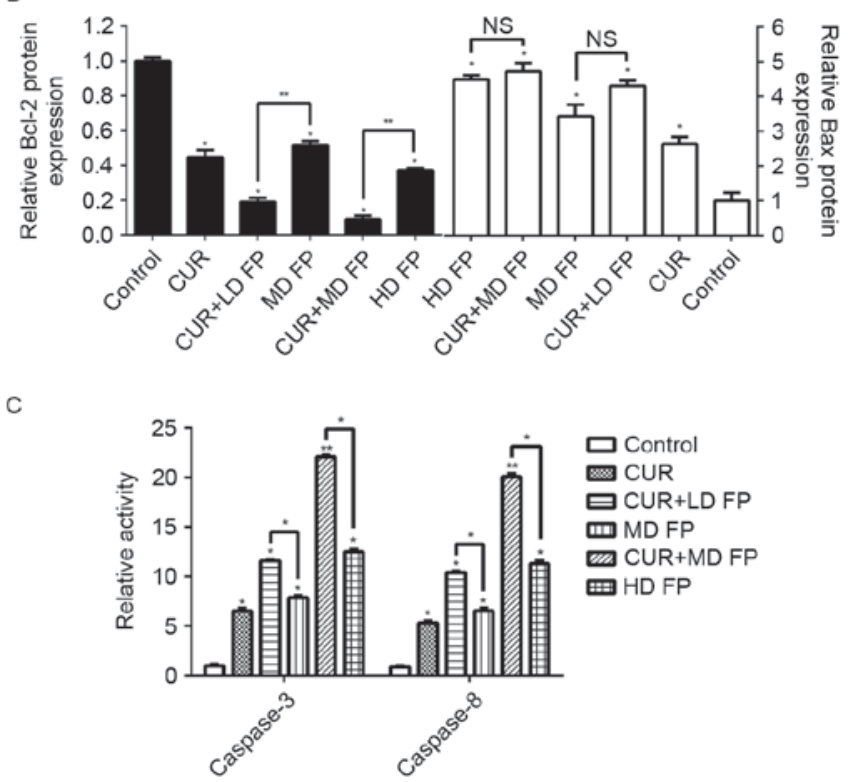

Figure 5. Effect of curcumin and/or FP on the expression and activity of apoptosis-associated proteins in MGC-803 cells. (A) Western blot analysis of Bcl-2 and Bax expression in MGC-803 cells treated with curcumin and/or FP for $24 \mathrm{~h}$. $\beta$-actin was used as the internal reference. (B) Quantification of the expression level of Bcl-2 and Bax in MGC-803 cells following treatment with curcumin and/or FP for $24 \mathrm{~h}$. (C) Activities of caspase-3 and caspase- 8 in MGC-803 cells treated with curcumin and/or FP for $24 \mathrm{~h}$. Data are presented as the mean \pm standard deviation and are representative of $\geq 3$ independent experiments. ${ }^{*} \mathrm{P}<0.05,{ }^{* *} \mathrm{P}<0.01$. FP, 5 '-fluorouracil plus cisplatin; CUR, curcumin; LD, low-dose; MD, low-dose; HD, high-dose; NS, not significant; Bcl-2, B-cell lymphoma 2; Bax, Bcl-2-associated X protein.

differentiation of MDSCs, and interfere with the interaction between MDSCs and cancer cells and to suppress tumor growth (30). In addition, curcumin has been demonstrated to protect against chemoresistance in human gastric cancer cells by downregulating nuclear factor $\kappa$-light chain enhancer of activated $\mathrm{B}$ cells $(\mathrm{NF}-\kappa \mathrm{B})$ and subsequent $\mathrm{NF}-\kappa \mathrm{B}-$ mediated anti-apoptotic genes, including Bcl-2 and Bcl-extra large in the SGC 7901 human gastric cancer cell line (31). Curcumin suppresses proliferation and invasion in human gastric cancer cells by downregulating serine/threonine-protein kinase PAK1 activity and cyclin D1 expression (32). A previous study identified that the anti-metastatic effect of curcumin on endometrial carcinoma is associated with inhibition of the expression and activity of MMP-2 and -9 via downregulation of the ERK signaling pathway (33).

Previous studies have investigated the effects of combination chemotherapy with curcumin. Curcumin and its analogues (PGV-0 and PGV-1) enhance the cytotoxicity of doxorubicin in MCF-7 cells via the inhibition of human epidermal growth factor activity and $\mathrm{NF}-\kappa \mathrm{B}$ activation (34). Curcumin may enhance the antitumor activity of docetaxel in ATC cells by interfering with $\mathrm{NF}-\kappa \mathrm{B}$ and cyclooxygenase-2 (35). However, the anticancer effects of curcumin combined with FP in gastric cancer cells have not yet been reported, to the best of our knowledge. The present study investigated the synergistic effects of curcumin and FP chemotherapy on the MGC-803 human gastric cancer cell line using an MTT assay, flow cytometry, double AO/EB fluorescent staining, a colony formation assay and a Transwell migration assay. The results demonstrated that curcumin combined with low-dose FP or medium-dose FP enhances the effects of FP alone on cell viability and apoptosis. Therefore, the side effects of FP may be reduced via the co-administration of curcumin and low-dose FP chemotherapy, rather than the administration of FP chemotherapy alone.

The present study investigated the molecular mechanisms underlying the anticancer effects of curcumin combined with FP using western blot analyses, and the results suggested that the combination of curcumin and FP can effectively increase Bax expression whilst also decreasing Bcl-2 expression. The Bcl-2, Bax, caspase-3 and caspase-8-associated signaling pathways have been reported to be associated with $\mathrm{GC}(36,37)$. In addition, the results from the caspase- 3 and caspase- 8 activity assay kits demonstrated that the combination of curcumin and FP could significantly promote the activity of caspase- 3 and caspase-8.

In conclusion, curcumin enhances the anticancer effects of FP in MGC-803 cells by decreasing cell viability, inhibiting colony formation, inhibiting cell migration and inducing apoptosis via the activation of caspase-3/-8, downregulation of Bcl-2 and upregulation of Bax. These results suggest that curcumin may be used in synergy with chemotherapy regimen FP to treat patients with GC. Further studies are required in order to evaluate the efficacy of this combined treatment in vivo.

\section{Acknowledgements}

The present study was supported by the Nature Science Foundation of Hubei Province (grant no. 2013CFB067).

\section{References}

1. Chen Y, Li Y, Wang H, Lu J, Jin M and Zhang Z: Maternal gastric carcinoma with metastasis to the placenta: A case report. Oncol Lett 8: 2509-2510, 2014

2. Nagini S: Carcinoma of the stomach: A review of epidemiology, pathogenesis, molecular genetics and chemoprevention. World J Gastrointest Oncol 4: 156-169, 2012.

3. Ferlay J, Soerjomataram I, Dikshit R. Eser S, Mathers C, Rebelo M, Parkin DM, Forman D and Bray F: Cancer incidence and mortality worldwide: Sources, methods and major patterns in GLOBOCAN 2012. Int J Cancer 136: E359-E386, 2015.

4. Yang D, Hendifar A, Lenz C, Togawa K, Lenz F, Lurje G, Pohl A, Winder T, Ning Y, Groshen S and Lenz HJ: Survival of metastatic gastric cancer: Significance of age, sex and race/ethnicity. J Gastrointest Oncol 2: 77-84, 2011.

5. Pulido-Moran M, Moreno-Fernandez J, Ramirez-Tortosa $\mathrm{C}$ and Ramirez-Tortosa M: Curcumin and health. Molecules 21: 264, 2016.

6. Aggarwal BB, Kumar A, Aggarwal MS and Shishodia S: Curcumin derived from turmeric (Curcuma longa): A spice for all seasons. Phytopharm Cancer Chemo Prev 349-387, 2005.

7. Lao CD, Ruffin MT IV, Normolle D, Heath DD, Murray SI, Bailey JM, Boggs ME, Crowell J, Rock CL and Brenner DE: Dose escalation of a curcuminoid formulation. BMC Complement Altern Med 6: 10, 2006. 
8. Kamat AM, Tharakan ST, Sung B and Aggarwal BB: Curcumin potentiates the anticancer effects of Bacillus Calmette-Guerin against bladder cancer through the downregulation of NF-kappaB and upregulation of TRAIL receptors. Cancer Res 69: 8958-8966, 2009.

9. Kunnumakkara AB, Anand P and Aggarwal BB: Curcumin inhibits proliferation, invasion, angiogenesis and metastasis of different cancers through interaction with multiple cell signaling proteins. Cancer Lett 269: 199-225, 2008

10. Mahajanakatti AB, Murthy G, Sharma N and Skariyachan S: Exploring inhibitory potential of Curcumin against various cancer targets by in silico virtual screening. Interdiscip Sci 6 : $13-24,2014$

11. Van Cutsem E: The treatment of advanced gastric cancer: New findings on the activity of the taxanes. Oncologist 9 (Suppl): S9-S15, 2004.

12. LoRusso P, Pazdur R, Redman BG, Kinzie J and Vaitkevicius V: Low-dose continuous infusion 5-fluorouracil and cisplatin: Phase II evaluation in advanced colorectal carcinoma. Am J Clin Oncol 12: 486-490, 1989

13. Bouché O, Ychou M, Burtin P, Bedenne L, Ducreux M, Lebreton G, Baulieux J, Nordlinger B, Martin C, Seitz JF, et al: Adjuvant chemotherapy with 5-fluorouracil and cisplatin compared with surgery alone for gastric cancer: 7-year results of the FFCD randomized phase III trial (8801). Ann Oncol 16: $1488-1497,2005$

14. Nakata B, Sowa M, Tsuji A, Kamano T, Sasaki K, Fukunaga Y, Takahashi M, Tsujitani S, Mikami Y, Mitachi Y, et al: Continuous infusion of 5-fluorouracil with versus without low-dose, consecutive administration of cisplatin in advanced colorectal cancer. A prospective randomized phase II study. J Exp Clin Cancer Res 26: 51-60, 2007

15. Kim R, Nishimoto N, Inoue H, Yoshida K and Toge T: An analysis of the therapeutic efficacy of protracted infusion of low-dose 5 -fluorouracil and cisplatin in advanced gastric cancer. J Infect Chemother 6: 222-228, 2000.

16. Xingde W, Xingqiu H, Chengxian G, et al: Long-period virulent test of Curcumin. J Zhejiang College TCM 24: 61-65, 2000.

17. Perkins S, Verschoyle RD, Hill K, Parveen I, Threadgill MD, Sharma RA, Williams ML, Steward WP and Gescher AJ: Chemopreventive efficacy and pharmacokinetics of curcumin in the $\mathrm{min} /+$ mouse, a model of familial adenomatous polyposis Cancer Epidemiol Biomarkers Prev 11: 535-540, 2002.

18. Aggarwal BB, Sundaram C, Malani N and Ichikawa H: Curcumin: The Indian solid gold. Adv Exp Med Biol 595: 1-75, 2007.

19. Esatbeyoglu T, Huebbe P, Ernst IM, Chin D, Wagner AE and Rimbach G: Curcumin-from molecule to biological function. Angew Chem Int Ed Engl 51: 5308-5332, 2012.

20. Calaf GM, Echiburú-Chau C, Roy D, Chai Y, Wen G and Balajee AS: Protective role of curcumin in oxidative stress of breast cells. Oncol Rep 26: 1029-1035, 2011.

21. Li PM, Li YL, Liu B, Wang WJ, Wang YZ and Li Z: Curcumin induces MHCC97H liver cancer cell apoptosis by activating ROS/TLR-4/caspase signaling pathway. Asian Pac J Cancer Prev 15: 2329-2334, 2014.

22. Wu SH, Hang LW, Yang JS, Chen HY, Lin HY, Chiang JH, Lu CC, Yang JL, Lai TY, Ko YC and Chung JG: Curcumin induces apoptosis in human non-small cell lung cancer NCI-H460 cells through ER stress and caspase cascade and mitochondria-dependent pathways. Anticancer Res 30: 2125-2133, 2010.

23. Goel A and Aggarwal BB: Curcumin, the golden spice from Indian saffron, is a chemosensitizer and radiosensitizer for tumors and chemoprotector and radioprotector for normal organs. Nut Cancer 62: 919-930, 2010.
24. Subramaniam D, Ponnurangam S, Ramamoorthy P, Standing D, Battafarano RJ, Anant S and Sharma P: Curcumin induces cell death in esophageal cancer cells through modulating notch signaling. PLoS One 7: e30590, 2012.

25. Gupta SC, Patchva S and Aggarwal BB: Therapeutic roles of curcumin: Lessons learned from clinical trials. AAPS J 15 195-218, 2013.

26. Su CC, Wang MJ and Chiu TL: The anti-cancer efficacy of curcumin scrutinized through core signaling pathways in glioblastoma. Int J Mol Med 26: 217-224, 2010.

27. Zhu L, Han MB, Gao Y, Wang H, Dai L, Wen Y and Na LX: Curcumin triggers apoptosis via upregulation of $\mathrm{Bax} / \mathrm{Bcl}-2$ ratio and caspase activation in SW872 human adipocytes. Mol Med Rep 12: 1151-1156, 2015.

28. Sintara K, Thong-Ngam D, Patumraj S and Klaikeaw N: Curcumin attenuates gastric cancer induced by N-Methyl-N-nitrosourea and saturated sodium chloride in rats. J Biomed Biotechnol 2012: 915380, 2012

29. Wu J, Lu WY and Cui LL: Inhibitory effect of curcumin on invasion of skin squamous cell carcinoma A431 cells. Asian Pac J Cancer Prev 16: 2813-2818, 2015.

30. Tu SP, Jin H, Shi JD, Zhu LM, Suo Y, Lu G, Liu A, Wang TC and Yang CS: Curcumin induces the differentiation of myeloid-derived suppressor cells and inhibits their interaction with cancer cells and related tumor growth. Cancer Prev Res (Phila) 5: 205-215, 2012.

31. Yu LL, Wu JG, Dai N, Yu HG and Si JM: Curcumin reverses chemoresistance of human gastric cancer cells by downregulating the NF-кB transcription factor. Oncol Rep 26: 1197-1203, 2011 .

32. Cai XZ, Wang J, Li XD, Wang GL, Liu FN, Cheng MS and Li F: Curcumin suppresses proliferation and invasion in human gastric cancer cells by downregulation of PAK1 activity and cyclin D1 expression. Cancer Biol Ther 8: 1360-1368, 2009.

33. Chen Q, Gao Q, Chen K, Wang Y, Chen L and Li XU: Curcumin suppresses migration and invasion of human endometrial carcinoma cells. Oncol Lett 10: 1297-1302, 2015.

34. Meiyanto E, Putri DD, Susidarti RA, Murwanti R, Sardjiman, Fitriasari A, Husnaa U, Purnomo $\mathrm{H}$ and Kawaichi M: Curcumin and its analogues (PGV-0 and PGV-1) enhance sensitivity of resistant MCF-7 cells to doxorubicin through inhibition of HER2 and NF- $\kappa$ B activation Asian Pac J Cancer Prev 15: 179-184, 2014

35. Hong JM, Park CS, Nam-Goong IS, Kim YS, Lee JC, Han MW, Choi JI, Kim YI and Kim ES: Curcumin enhances docetaxel-induced apoptosis of 8505C anaplastic thyroid carcinoma cells. Endocrinol Metab (Seoul) 29: 54-61, 2014.

36. Xu JD, Cao XX, Long ZW, Liu XP, Furuya T, Xu JW, Liu XL, $\mathrm{De} \mathrm{Xu} Z$, Sasaki K and Li QQ: BCL2L10 protein regulates apoptosis/proliferation through differential pathways in gastric cancer cells. J Pathol 223: 400-409, 2011.

37. Barrezueta LF, Oshima CT, Lima FO, De Oliveira Costa H, Gomes TS, Neto RA and De Franco MF: The intrinsic apoptotic signaling pathway in gastric adenocarcinomas of Brazilian patients: Immunoexpression of the Bcl-2 family (Bcl-2, Bcl-x, Bak, Bax, Bad) determined by tissue microarray analysis. Mol Med Rep 3: 261-267, 2010. 